\title{
Political implications of natural disasters: regime consolidation and political contestation
}

\author{
E. Hörhager \\ Department of Political Science, Goethe University Frankfurt, Germany
}

\begin{abstract}
Just as disaster vulnerability is mediated by a country's political system, disasters can have major effects on political stability and political legitimacy. Politicization occurs when disasters as events in the political landscape are taken over by actors for political causes. A three-phase analytical model for disaster politicization in authoritarian contexts is inductively derived from the empirical evidence of the 12 May 2008 Wenchuan earthquake in China. This model theorizes the parallel development in the political discourse of consensus-based and contentious political mobilization surrounding a disaster. On the one hand, disasters can be framed as a consensus crisis to increase the political capacity and legitimacy of those in power. In opposition, they can also be framed to support contentious social claims. The disaster becomes a political issue, and the victims are no longer individual and passive disaster victims, but whole social groups advancing grievances and claims towards those in power. This process can have particularly important implications in a non-democratic political context. Disasters are intervening factors exogenous to the political system, and their effects can escape the control of those in power. Disasters can become unforeseen yet powerful factors in an otherwise limited space for political contestation.
\end{abstract}

Keywords: natural disasters, disaster politicisation, China, consensus crisis, political mobilization.

\section{Introduction}

As with other types of disasters, natural disasters are political. Political choices such as those about resource distribution, as well as socio-economic institutions and power structures influence the level and distribution of individual 
vulnerability to natural disasters. At the same time, disasters can produce notable effects on political processes when they rupture the every-day workings of society. Disasters can be politicized in that they raise questions on how to protect society from risks and are subject to debate and contestation in the public sphere.

China has numerous disaster-prone areas among its territory and is one of the countries in the world most severely affected by natural disasters. People in China face almost every type of natural disaster, every year, affecting on average between 200 million and 370 million people (UNISDR [1]). Historically, Chinese dynastic rule presents us with one of the longest traditions of disaster risk reduction and disaster mitigation practices. This changed when the People's Republic was founded in 1949 and continued up to the death of Mao in 1976, which was also when the devastating Tangshan earthquake occurred. During this time period, political obstacles stood in the way of continuing this earlier historic tradition and furthering it based on the newest scientific developments (Ross [2]). With the opening up and reform period since the 1980s, China's leaders have slowly started building a disaster management system focused on disaster prevention. The average number of disaster provoked deaths has been on the decline, even though the economic costs of disasters in China have been rising.

Disasters rupture the everyday workings of society by bringing a large number of people back to the level of basic survival. As one of the state's functions is protecting the population, a well-resourced and managed response from governments is necessary in order to avoid a political crisis (Olson and Gawronski [3]). The Chinese communist party (CCP) has, through a discrete balancing act between continuity and adaptability, remained in power for over 65 years despite innumerable disasters. It seems that natural disasters have not largely affected regime legitimacy in the past.

A disastrous earthquake with its epicenter in Wenchuan, Sichuan Province occurred on 12 May 2008, right after ethnic riots in the same province in March and before the Summer Olympics in Beijing. The Wenchuan earthquake stands out in terms of its catastrophic dimensions, with around 70,000 lives lost. It also caught the attention of numerous scholars of Chinese civil society (see Xu [4] for a summary). However, these studies have mainly been limited to the role of NGOs in the Wenchuan earthquake. At the same time, the literature on disaster politics, which has known a recent upsurge due to the 'Katrina effect' (see Olson and Gawronski [3] for a review of this literature), has in general focused on looking at democratic political systems or at regime change and new democracies. This study attempts to tackle the case of disasters in authoritarian regimes being used both as a means for regime consolidation and for political contestation. It attempts to shed some light on the black box of political mobilization in authoritarian countries and to take seriously the interplay between politics and disasters in such regime types.

Even though the earthquake was far from causing political instability to the point of regime transition, a closer analysis of the catastrophic earthquake will show that there has been a significant process of disaster politicization in China underway ever since 2008. This is all the more remarkable as natural disasters are seen to be less prone to causing political contestation than other types of 
disasters where blame is clearly attributable and can easily be placed on public authorities. Despite vulnerability to disasters being socially mediated natural disasters are, in contrast, still easily and frequently attributed to natural or divine forces if not simply to fate. Looking at the way natural disasters are politicized in a seemingly stable authoritarian regime is therefore of even greater interest. The following section will look at how this disaster become politicized in a context of limited space for public contestation and what forms of mobilization it provoked in the process.

\section{From consensus to contention in the wake of natural disasters}

Are natural disasters crises in which society pulls itself together in newfound unity in order to rescue victims and reconstruct affected areas? Or do natural disasters rather produce a situation in which social inequality and conflict comes to the fore? Based on various empirical studies, both of these scenarios have found their way into social scientists' conceptualizations of natural disasters. On the one hand, the consensus-producing effect of natural disasters was advanced early on in disaster research through the concept of 'therapeutic communities' (Fritz [5]). Natural disasters can be thought of as consensus crises because they are followed by a situation in which society is in "general overall agreement about goals and about what should be done." (Quarantelli [6]) However, this conceptualization has been largely marginalized in favor of the study of how disasters provoke unrest and political change in society (Pelling and Dill [7]). This trend in disaster research is connected with the rise of the 'vulnerability' concept, which places its emphasis on dimensions of stratification and social inequality exacerbated during and after disasters. The following case study looks for elements of both a consensus crisis and of contentious mobilization for political change in the aftermath of the Wenchuan earthquake.

\subsection{Consensus crisis and regime consolidation}

In an authoritarian context change in the political system undermines the current elite's grip on power and can often be characterized as contentious. However, if disasters provoke a consensus crisis this does not necessarily signal an absence of change. Consensus crises include an element of cooperative action and are far from implying a state of societal passivity. In the Chinese context of authoritarianism consensus crises can be further conceptualized as involving consensual and cooperative action between the government, state organs and different sectors of society (Xu [4]). This involves the framing of the disaster as provoking a societal consensus and the mobilization of these various groups of actors towards a common goal in reaction to the disaster.

The Chinese central government directs the country's natural disaster response through the National Committee for Disaster Reduction and the Emergency Management Office of the State Council. In line with the Confucian conception of humanitarianism, the state as a moral agent dominates as the main 
humanitarian actor in China (Hirono [8]). Responding to the Wenchuan earthquake was therefore first and foremost an immediate political task. The Chinese disaster management system is based on vertical inter-governmental governance (Wei et al. [9]). After such a large scale earthquake as in 2008, the Earthquake Relief Headquarters is responsible for coordinating the military and civilian state actors engaged in relief and reconstruction. The central government busied itself with presenting its version of the crisis to the public through staterun mass media, which serves the purpose of "propaganda, organization, mobilization and control." (Wu [10]) Immediately after the Wenchuan earthquake struck on 12 May 2008, the People's Daily (Renmin ribao), mouthpiece of the CCP and most widely circulated Chinese newspaper, started framing the natural disaster by portraying it and the government's own actions in a specific way. This included focusing relief efforts on "the priority of saving lives", underlining the government's decisive action, and promoting an emotional discourse of national unity (Renmin [11]). In terms of its actions, the government took unprecedented steps in incorporating civil society actors and private actors into the relief and reconstruction effort.

An extensive media content analysis of the People's Daily's coverage of Wenchuan was done by Yuanpeng Liu [12]. It shows how the main focus is placed on the actions of the central government and individual political leaders instead of on the conditions in the disaster area. This meant that mass media scrutiny was kept away from potentially contentious technical issues. From the start, the earthquake was top-priority for the CCP's leadership, with President $\mathrm{Hu}$ issuing instructions and Premier Wen on-site only hours after the earthquake choosing to act as commander of the Earthquake Relief Headquarters. In an unusual move, Premier Wen did not hesitate to exert public pressure on the commanders of the military rescue operation, thus underscoring the need for state unity under central government leadership. Many highly symbolic acts by political leaders, demonstrating their sacrificial dedication through self-imposed privations, were relayed in the media. They played on an emotional register of solidarity and compassion and were complimented by the high profile given to the relief efforts of individual volunteers rushing to the quake zone in both onand offline media. Just as emotion-laden, reporting on the situation of victims focused on unlikely stories of individual survivals and hope-filled descriptions of communities' efforts at resilience. These reports avoided the contested topics of social vulnerability and responsibility by relating victimhood and survival back to the destiny and willpower of individuals. Their narrative of heroism and sacrifice formed a connecting link between the figure of the individual victim, the figure of the individual volunteer, and individual CCP leaders. This provided an emotional basis for consensual feelings of national unity.

The consensual societal mobilization was epitomized in the slogan "we are all Wenchuan people today" (Renmin [13]) promoted in the state-led discourse and on social media. It was put into action in the unprecedented manner with which non-state actors were involved after the earthquake. In fact, Bin Xu [4] qualified the Sichuan earthquake as a consensus crisis based on the opportunity for legitimate large-scale civil society participation in humanitarian activities. With 
the semi-governmental networks such as the Red Cross overwhelmed in their capacity, officials in Sichuan called upon the public for urgent donations and encouraged the participation of ordinary citizens as volunteers. Both public donations to civil society organizations and civil society activities themselves had been largely restricted before the earthquake. In its aftermath the legal restrictions on NGOs and charitable individuals were loosened and local governments cooperated with certain NGO networks. This was coupled with a general reduction of repressive measures towards civil society which would have been taken by the police during normal times. An element of durable political change was introduced with institutional reforms legalizing private foundations following the emergency period and more long-term practices of cooperation between local governments and civil society associations.

In addition to these actions undertaken based on the needs of disaster response, a symbolic demonstration of solidarity with the earthquake victims was issued through the declaration, seven days after the earthquake, of a 3-day national mourning period. This was the first public mourning declared for ordinary citizens (Xu [14]) and further demonstrates how the consensus building effect of the disaster went far beyond prioritizing action and cooperation to solve immediate and technical problems. Instead, it fulfilled a broader political legitimizing function both in terms of output (effective government response to the disaster by incorporating all sectors of society in the relief effort), and in terms of symbolic political capital based on the expression of national unity. In conclusion, elements of both nationalism and Confucianism came into play in the government's efforts to frame the disaster as a consensus crisis aimed at consolidating its grip on power and increasing its legitimacy.

\subsection{Contentious mobilization and political contestation}

Disasters often create or reinforce a sense of identity among affected populations. In the state-mobilized consensus described above, certain individuals and their suffering or sacrifice become symbolically projected onto the national level. However, the Wenchuan earthquake also provoked the emergence of a number of individuals who had all experienced a similar loss, namely that of their (often only) child in the numerous collapsed school buildings. Their collective victimhood led to a new group identity based on a shared experience of vulnerability and inequality. This allowed them to transcend the individual level of suffering, all the while remaining apart from the national consensus as led by the party-state. In the chaotic situation following the disaster and with the emotional dynamic it created, new space for political contestation opened up.

There have been an increasing number of incidences of citizen collective action in China since the 1990s. Their suppression has been a priority for the central and local governments. Independent political action for the expression of collective grievances is difficult in China and often occurs spontaneously and in a short-lived manner. Social mobilization tends to emerge from local issues and involve tangible grievances and legitimate claims instead of representing a fullblown challenge to the authority of the party-state. Two notions that Bruun [15] puts forward are key to understanding the contentious mobilization which 
emerged after the earthquake around the issue of shoddy school building construction known as 'tofu-dreg construction' (Doufu zha xuexiao). These are the presence of a trigger event that changed the perception and motivation of those involved, and phase shifts which alter the alignment of the mobilization.

Corruption by local officials has become a focus of popular outrage and online citizen protest in recent years. In addition, the issue of property development and construction is highly sensitive because of widespread collusion between local governments and real-estate developers. Based on this background, the trigger event of the earthquake and the disproportionate collapse of school buildings in Beichuan and Wenchuan counties, which killed around 10,000 children, set off a process of gradual mobilization by the affected parents. In the days following the quake, parents held daily gatherings at the school sites. Soon individuals started to organize their groups to conduct meetings and hold marches to give them visibility and voice. They demanded official investigations into the school building construction in escalating clashes with local authorities. With international children's day on 1 June the issue began to receive coverage in the media and several civil engineers stepped forward to discuss possible flaws in construction. In response, the government quickly blocked the publishing of schoolchild death toll statistics and started censoring coverage of the issue. A month after the earthquake, in June 2008, local governments tried to break up the groups of parents and take away the mobilization's momentum by offering monetary compensation to individual parents conditional to the cessation of all protest activity. Nevertheless, groups of parents attempted to file lawsuits which were rejected by the district courts. It seemed that this local mobilization would wilt away faced with the strong suppression by authorities just as others had before it.

This is the point at which a phase shift intervenes, creating contention involving larger audiences and involving more actors. Bruun [15] describes, from a political mobilization perspective, the involvement of several high-profile activists and the increasing international media attention to show how they elevated the struggle of the parents from the local to the national level. Key figures were human rights activists Huang Qi and Tan Zuoren, as well as renowned artist/activist $\mathrm{Ai}$ Weiwei. The grievances of the parents were reformulated on a more abstract level around calls for more social equality, for the fight against cadre corruption and against the lack of governmental transparency. This phase shift has to be related back to the earthquake. The localized mobilization around the effects of the disaster - high vulnerability of schoolchildren in low-income districts - became contentious politicization of fundamental questions of social justice involving corruption and inequality. This phase shift occurred through the involvement of actors who were not affected by the disaster, but became active on behalf of the parents and thus attracted media attention to their cause. Activists and dissidents were a group excluded from the consensus based state mobilization of civil society, which focused on NGOs and associations without political missions. This understudied phenomenon was already described by Shefner [16] in his study of the 1992 Guadalajara sewer explosions in Mexico; he called the externally intervening activists contentious 
supporters. In the case of Mexico, the context was one of national political instability. In the Chinese case, however, the context is one of a fairly stable and repressive authoritarian regime where the costs of political contestation are high. The earthquake opened up a situational window of opportunity opened up for these activists in the otherwise systemic suppression of their mobilization efforts. The large media presence and the emotionally charged atmosphere after the earthquake provided a conducive opportunity structure for attempts to build a larger-scale movement.

Because of its appropriation by well-known dissidents, the effects of this contentious mobilization continued to be visible in the years that followed the earthquake despite the suppression of the parents. In 2008, environmental activist Tan Zuoren initiated a 'citizens' investigation' (Gongmin diaocha) leading to the establishment of a victim database. After he was detained and subsequently jailed in March 2009 for 'inciting subversion of state power', Ai Weiwei became involved in defending Tan Zuoren and the cause of the parents. He posted about the issue on his blog and continued to bring it up in his artwork and his interviews in the international press. Several documentary films were released on the case. Finally, after having kept silent on the results of its initial investigation into the school building collapse the Chinese government felt compelled to acknowledge the poor construction of many school buildings in China. The local government encouraged the parents to try to have a second child, and published official statistics on the number of schoolchild victims in May 2009. The issue of 'tofu-dreg construction' has continued to come up in subsequent earthquakes, such as the 2014 one in Ludian. This is an example of how legitimate claims and grievances, made visible through a natural disaster, became issues of social justice challenging regime authority. It has resulted in two competing narratives of the Chinese government's reaction to the disaster: the narrative of extremely successful and timely rescue and reconstruction efforts, challenged by the narrative of social vulnerability and inequality exacerbated by the disaster.

\section{Politicization and change}

Recent studies with a comparative approach have looked at multiple disasters over time in order to analyze their connection with political unrest in a quantitative manner. Two correlations have emerged from quantitative studies that are interesting for the case analyzed here, namely the politicization of disasters in authoritarian countries. The lower the level of pre-disaster political unrest and the higher the level of political repression in a country, the less likely political change following a disaster becomes (Drury and Olson [17]). Based on these two factors political change in stable authoritarian regimes following a disaster is highly unlikely. This conclusion rests, however, on a certain interpretation of political change. Conceptualizing earthquakes as critical junctures which cause irreversible change of a political regime makes change synonymous with regime transition or a change of government (Pelling and Dill [7]). At the same time, continuity becomes simply a situation of continued elite 
control. The empirical evidence discussed above shows that there are also more subtle yet important and lasting political changes which can be provoked by disasters, even in the context of what appears to be very stable authoritarian rule. This is because the post-disaster situation is one which favors mobilization.

The process of disaster politicization can trigger both consensus-based mass mobilization by the state typical of authoritarian regimes, as well as less frequent contestation-based political mobilization from within society. In the first case, the high operational demands of the catastrophe and the strong societal willingness to help in the post-disaster context led the Chinese government to rely on the cooperation of volunteers and civil society. In this type of consensus mobilization, the CCP exceptionally validated contributions from actors outside of the party-state and opened up new political space for them to take on a legitimate and constructive role in society. The second type of mobilization is initiated outside of the state apparatus and involves mobilization which contests the foundations for the consensus. One and the same disaster can therefore provide the political space for politicization in the direction of regime reinforcement as well as in the direction of political contestation. The mere involvement of non-state actors can trigger elements of lasting change in a political system where societal actors are kept passive under the dominance of the party-state. This involves more subtle political change through the strengthening of contentious forces and the institutionalization of new forms of state-civil society cooperation. Such political change has the potential to become highly significant in the long run.

From the empirical evidence presented above, it is possible to inductively extrapolate a 3-phase model of post-disaster politicization. The first phase is one of urgency directly following the trigger event. The immediate reaction to a natural disaster, spearheaded by the regime in power, is that of a consensus crisis. The shock at the devastation unites the state, the general population and different types of societal actors around the immediate need for rescue efforts. In a second phase, the unequal distribution of vulnerability becomes more obvious, leading to grievances and claims. This allows the formation of groups of victims which undermine the framing of all 'disaster victims' as well as of 'the nation' as a unitary groups. Finally, a third phase can occur if the grievances and claims expose fundamental issues of social justice which are not limited to the group of victims having first put them forward. In this case, the social mobilization can transcend the situational context of the disaster and can be translated into broader interests based on fundamental issues of vulnerability and social justice. In the authoritarian context, the transition to the third phase with a higher level of mobilization seems most likely through the intervention of contentious supporters who translate localized claims into interests aimed at political contestation.

The different types of mobilization present in this model engage diverse groups of actors and rely on their own logic and repertoire of political consensusbuilding or contestation. They are present in the national sphere at the same time, although at different levels in society and involving different actors. The almost spontaneously emerging consensus phase which follows in the wake of a disaster 
is sustained through a regime-supported discourse on national unity and solidarity. The next two phases are characterized by heightened complexity as new groups and alternative narratives emerge. What is important to note is that the different types of mobilization can continue to exist side by side and run in parallel to each other. The mobilization based on contention does not have to directly undermine the consensus-based discourse. If it aims criticism at the official relief and reconstruction efforts it can undermine the consensus. However, if it is aimed at uncovering elements of vulnerability or factors hampering resilience its claims can only implicitly challenge the former. Derived inductively from the Chinese case, this model needs to be tested in further research. It will be particularly important to isolate important systemic factors which contributed to the evolution of the three phases.

For policy makers and practitioners engaged in Disaster Risk Reduction (DRR), it is important to keep in mind the ambiguous nature of post-disaster politicization, in that it can be both based on a consensus crisis as well as on political contestation. Consensus crises are particularly tricky. On the surface, a consensus crisis is often interpreted as meaning less politicization and more straightforward disaster relief and reconstruction. On the one hand, it unites people in their effort for rescue and relief, yet on the other hand, it relies heavily on an emotional register which can marginalize criticism or even the mere public discussion of technical issues and be politically instrumentalized. This study has shown that consensus does not necessarily mean less political interference and more effective DRR. Instead, it can be instrumentalized by authoritarian regimes and undermine long-term vulnerability reduction. Looking at the process of contentious mobilization in China turns attention to the fact that issues of disaster vulnerability are inextricably linked to social justice and the accompanying political choices made in society. This means that the political system can be a highly constraining factor on disaster management aimed at reducing disaster vulnerability and that it is therefore vital to understand the way the political process affects DRR.

\section{Acknowledgement}

This publication was funded by the Volkswagen Foundation, issued within its initiative "Key Issues for Research and Society" for the research project "Protecting the Weak: Entangled processes of framing, mobilization and institutionalization in East Asia" (AZ 87 382) at the Interdisciplinary Centre for East Asian Studies (IZO), Goethe University, Frankfurt/Main.

\section{References}

[1] The United Nations Office for Disaster Risk Reduction (UNISDR), Disaster Reduction Report of the People's Republic of China (Translation), http://www.unisdr.org/2005/mdgs-drr/national-reports/ China-report.pdf 
[2] Ross, L., Earthquake Policy in China. Asian Survey, 24(7), pp. 773-787, 1984.

[3] Olson, R. S., \& Gawronski, V. T., Disasters as Critical Junctures? Managua, Nicaragua 1972 and Mexico City 1985. International Journal of Mass Emergencies and Disasters, 21(1), pp. 3-35, 2003.

[4] $\mathrm{Xu}, \mathrm{Bin}$, Consensus Crisis and Civil Society: The Sichuan Earthquake Response and State-Society Relations. The China Journal, 71, pp. 91-108, 2014.

[5] Fritz, C., Disaster. Contemporary Social Problems, Merton, R. \& Nisbet, R. (eds.), Harcourt, Brace and World: New York, pp. 651-694, 1961.

[6] Quarantelli, E. L., Emergent Accommodation Groups: Beyond Currrent Collective Behavior Typologies. Human Nature and Collective Behavior: Papers in Honor of Herbert Blumer, Blumer, H. \& Shibutani, T., (eds.), Prentice Hall: Englewood Cliffs, pp. 111-123 (p. 114), 1970. As quoted in $\mathrm{Xu}[4]$.

[7] Pelling, M., \& Dill, K., Disaster politics: tipping points for change in the adaptation of sociopolitical regimes. Progress in Human Geography, 34(1), pp. 21-37, 2010.

[8] Hirono, M., Three legacies of humanitarianism in China. Disasters, 37(s2), pp. 202-S220, 2013.

[9] Wei, Y.-M., J.-L. Jin and Q. Wang, Impacts of Natural Disasters and Disasters Risk Management in China: The Case of China's Experience in Wenchuan Earthquake. Economic and Welfare Impacts of Disasters in East Asia and Policy Responses. Sawada, Y. and S. Oum (eds.), ERIA Research Project Report 2011-8, ERIA: Jakarta, pp. 641-675, 2012.

[10] Wu, G., Command Communication: The Politics of Editorial Formulation in the People's Daily. The China Quarterly, 137, pp. 194-211 (p. 194), 1994.

[11] Renmin ribao, Sichuan sheng wenchuan xian fasheng 7.8 ji dizhen, $\mathrm{Hu}$ Jintao zuochu yhongyao yhishi, yaoqiu jinkuai qiangjiu shangyuan, que bao zaiqu renmin qunzhong shengming anquan, Wen Jiabao fu zaiqu xianchang zhihui kangzhen jiuzai gongzuo (四川省汶川县发生 7.8 级地 震胡锦涛作出重要指示, 要求尽快抢救伤员, 确保灾区人民群众生命 安全温家宝赴灾区现场指挥抗震救灾工作, 7.8 magnitude earthquake in Wenchuan County, Sichuan Province, $\mathrm{Hu}$ Jintao issued important instructions to rescue the wounded as soon as possible and ensure safety of the people in the disaster zone, Wen Jiabao went to the scene to direct disaster relief work), 12.05.2008.

[12] Liu, Yuanpeng, Renmin Ribao Wenchuan dizhen baodao yanjiu (人民日 报》汶川地震报道研究, Media Content Analysis of the People's Daily reporting on Wenchuan earthquake), Lanzhou University Master's Thesis, http://wenku.baidu.com/view/5c627aa2f524ccbff121847b.html

[13] Renmin ribao, zhongduo wangyou shenqing biaoda jintian, women dou shi wenchuan ren (众多网友深情表达 今天, 我们都是汶川人, Many 
netizens affectionately proclaim: today, we are alle Wenchuan people), 15.05.2008.

[14] $\mathrm{Xu}, \mathrm{B}$., For whom the bell tolls: state-society relations and the Sichuan earthquake mourning in China. Theory and society, 42(5), pp. 509-542, 2013.

[15] Bruun, O., Social movements, competing rationalities and trigger events: The complexity of Chinese popular mobilizations. Anthropological Theory, 13(3), pp. 240-266, 2013.

[16] Shefner, J., Pre- and Post-Disaster Political Instability and Contentious Supporters: A Case Study of Political Ferment. International Journal of Mass Emergencies and Disasters, 17(2), pp. 137-160, 1999.

[17] Drury, A. C. \& Olson, R. S., Disasters and Political Unrest: An Empirical Investigation. Disasters and Political Unrest, 6(3), pp. 153-161, 1998. 